\title{
Contents of essential and toxic mineral elements in Swedish market-basket diets in 1987
}

\author{
BY WULF BECKER \\ Nutrition Division, National Food Administration, Uppsala, Sweden \\ AND JORMA KUMPULAINEN \\ Agricultural Research Centre, Central Laboratory, Jokioinen, Finland
}

(Received 2I June 1990-Accepted 4 January 199I)

\begin{abstract}
Market baskets containing sixty food items included in the average Swedish diet were purchased from three shops in four major Swedish cities during autumn 1987. Food items were selected on the basis of food-balance-sheet data. Freeze-dried homogenates representative of each city were analysed for twelve essential or toxic mineral elements. The energy content of the market baskets $(11.5 \mathrm{MJ})$ corresponded to the reference value for male adults. At this energy level the contents of calcium $(1180 \mathrm{mg})$, magnesium (300 mg), iron (16 mg), zinc (12 mg) and selenium (44 $\mu \mathrm{g})$ were above or close to the Swedish recommended daily intakes. The contents of manganese $(3.7 \mathrm{mg})$ and molybdenum $(150 \mu \mathrm{g})$ were within and that of copper (1-2 mg) was below the safe and adequate intake values given in the US recommended dietary allowance (Food and Nutrition Board, National Research Council, 1989). The content of nickel was $82 \mu \mathrm{g}$. The contents of lead $(17 \mu \mathrm{g})$, cadmium $(12 \mu \mathrm{g})$ and mercury $(1.8 \mu \mathrm{g})$ in the daily diet were low compared with the provisional tolerable intakes set by the Joint Food and Agriculture Organization/World Health Organization Expert Committee on Food Additives (World Health Organization, 1972, 1989). The market-basket contents of $\mathrm{Ca}, \mathrm{Mg}, \mathrm{Fe}$ and $\mathrm{Zn}$ calculated from values in the Swedish food composition tables were close to the analysed values, indicating that the Swedish food tables provide relevant information for the estimation of the dietary supply of these elements.
\end{abstract}

Market-basket diets: Essential minerals: Toxic minerals: Swedish diet

Both the analysis of market baskets and that of duplicate portions are useful methods for assessing dietary intake of various compounds within a population. They can also be used to check the quality of existing food composition data. Previous studies have employed various approaches, depending on the aim and resources available. In some studies food intake data have been used as a basis for the selection of market-basket samples or duplicate portions (Varo et al. 1980); Pennington et al. 1986; Pennington \& Jones, 1987; van Dokkum et al. 1989), while in others, data from national food balance sheets (Varo \& Koivistoinen, 1980; Slorach et al. 1983; Kumpulainen et al. 1987b; Ohlander et al. 1991) or hospital diets (Sinisalo et al. 1989) have been used. Due to differences in methodologies, results from various studies expressed on a daily intake basis are difficult to compare directly.

After the Chernobyl accident in May 1986, the Swedish National Food Administration (NFA) started a project to monitor the level of radioactive caesium in the diet of different regions and population groups. The collection of representative 'market baskets' from various parts of the country constituted the major part of the project (Ohlander et al. 1991). As part of the Sub-network E programme of the Food and Agriculture Organization 
European Cooperative Research Network on Trace Elements (Kumpulainen \& Tahvonen, 1989), market baskets from four major cities in Sweden were collected with the aim of studying the intakes of mineral elements. In the present paper, results from the analysis of nutritionally-important mineral elements are reported and compared with those calculated from data in food tables.

\section{MATERIALS AND METHODS}

The market-basket study was originally designed to obtain information on the dietary content of radioactive $\mathrm{Cs}$ in various regions of Sweden. The background and details of the present study have been described elsewhere (Ohlander et al. 1991). In the present study, market food baskets were formed from food items purchased in Malmö, Göteborg, Stockholm and Sundsvall. These towns represent the major geographical regions and population centres in Sweden.

\section{Composition and purchase of the market baskets}

The choice of food included in the basket was based on the consumption statistics (food balance sheets) from the National Agricultural Market Board using the definite values for the year of 1983 (Statens jordbruksnämnd, 1986). These data give the consumption of foodstuffs combined into groups. In order to produce a shopping list to be used in all the cities alike, food groups had to be broken down into single items which was done using the Market Board's lists of items constituting each food group and their market shares in relation to each other.

The study's shopping list consisted of sixty foods and beverages, covering $76 \%$ of the total annual consumption expressed in $\mathrm{kg} /$ person (Tables 1 and 2). For each of the foods the average consumption was at least $0.5 \mathrm{~kg} /$ person. Alcoholic beverages (including export beer) were, however, not included when the baskets were designed, since they were not considered a significant source of radioactivity. Water was omitted for the same reason and, therefore, coffee and tea were also excluded.

This basket was purchased in the four chosen cities from three separate grocery shops representing the three major wholesale chains in Sweden. The market baskets were purchased during October 1987.

Purchases were made by staff from the local health authorities. Each shopper was instructed to act as an ordinary customer taking advantage of bargain prices, etc. within the limits of the shopping list. The day of purchase was decided upon in advance and the food baskets were, thereafter, immediately transported to the National Food Administration in Uppsala.

\section{Preparation of the food samples}

From each food basket a sample was prepared to represent $1 \%$ of the annual consumption of solid foods (Table 1) and $0.5 \%$ of the liquid foods (Table 2). In weighing subsamples of foodstuffs, due consideration was given to the fact that the consumption data are based on sales figures including non-edible parts such as peel and bone. Therefore, the amount equal to the average percentage of waste for each food item was deducted from the subsample.

All solid foods were homogenized in a food processor equipped with a titanium blade to minimize metal contamination. Meats were minced frozen and mixed with the other foods to form a solid homogenate $\left(\mathrm{A}_{\mathrm{s}}\right)$. Half this homogenate $(1400 \mathrm{~g})$ was mixed with the fluids $\left(A_{F} ; 1160 \mathrm{~g}\right)$ to form a homogenate $B$ representing each of the three grocery shops. From each of the three $\mathrm{B}$ homogenates $350 \mathrm{~g}$ was mixed to form a homogenate $\mathrm{C}$, representing 
Table 1. Per capita consumption of solid foods included in the Swedish 'market basket'* ( $\mathrm{kg} /$ person per year)

\begin{tabular}{|c|c|c|c|c|c|}
\hline Potatoes & $65 \cdot 2$ & Falu-sausage $\S$ & $5 \cdot 3$ & Oats, rolled & $2 \cdot 4$ \\
\hline Sugar & $19 \cdot 9$ & Meatballs & $5 \cdot 2$ & Breakfast cereals & 1.8 \\
\hline Apples & $17 \cdot 0$ & Beef knuckle & $5 \cdot 0$ & Cod, frozen & 1.8 \\
\hline Wheat flourt & $14 \cdot 6$ & Cabbage & $4 \cdot 9$ & Liver paste & 1.7 \\
\hline French loaf & $13 \cdot 9$ & Chocolate & 4.9 & Mettwurst, smoked** & $1 \cdot 7$ \\
\hline Bread, wheat + rye & $12 \cdot 3$ & Onions & 3.9 & Peas, frozen & $1 \cdot 4$ \\
\hline Eggs & $11 \cdot 2$ & Chicken & 3.9 & Peaches & 1.4 \\
\hline Pork loin & $10 \cdot 7$ & Butter & $3 \cdot 6$ & Cauliflower & $1 \cdot 2$ \\
\hline Bananas & $8 \cdot 6$ & Lettuce & $3 \cdot 5$ & Marshmallows & $1 \cdot 1$ \\
\hline Oranges & $8 \cdot 1$ & & & Ham, smoked & $0 \cdot 9$ \\
\hline Hard cheese ( $28 \%$ fat) & $7 \cdot 7$ & Hot dogs & $3 \cdot 2$ & Cottage cheese & $0 \cdot 9$ \\
\hline Ice-cream & 6.6 & Lingonberry jam\| & $3 \cdot 0$ & Baltic herring & 0.9 \\
\hline Carrots & $6 \cdot 0$ & Sweet wheat bread $\uparrow$ & $2 \cdot 8$ & Bacon & 0.8 \\
\hline Margarine & $5 \cdot 8$ & Moose meat & $2 \cdot 8$ & Lamb & $0 \cdot 7$ \\
\hline Pears & $5 \cdot 7$ & Pasta & $2 \cdot 7$ & Spinach & $0 \cdot 7$ \\
\hline Crispbread, rye $\ddagger$ & $5 \cdot 7$ & Rice & $2 \cdot 7$ & Beetroot & $0 \cdot 7$ \\
\hline Tomatoes & $5 \cdot 5$ & Strawberries & $2 \cdot 7$ & Cod fillet, fresh & $0 \cdot 6$ \\
\hline \multirow[t]{2}{*}{ Cucumber } & $5 \cdot 3$ & Grapes & $2 \cdot 4$ & & \\
\hline & & & & Total & $313 \cdot 0$ \\
\hline
\end{tabular}

* For details, see p. 152.

$\uparrow$ Extraction rate $72 \%$.

\$ Whole-meal rye crispbread.

$\S$ Sausage with $400-500 \mathrm{~g}$ meat $/ \mathrm{kg}$, fat content about $230 \mathrm{~g} / \mathrm{kg}$

$\|$ Fruit content about $400 \mathrm{~g} / \mathrm{kg}$, sugar content about $400 \mathrm{~g} / \mathrm{kg}$.

T Corresponds to buns.

** Smoked sausage with $500 \mathrm{~g}$ meat $/ \mathrm{kg}$, fat content about $350 \mathrm{~g} / \mathrm{kg}$.

Table 2. Per capita consumption of beverages included in the Swedish 'market basket'* ( $k g /$ person per year)

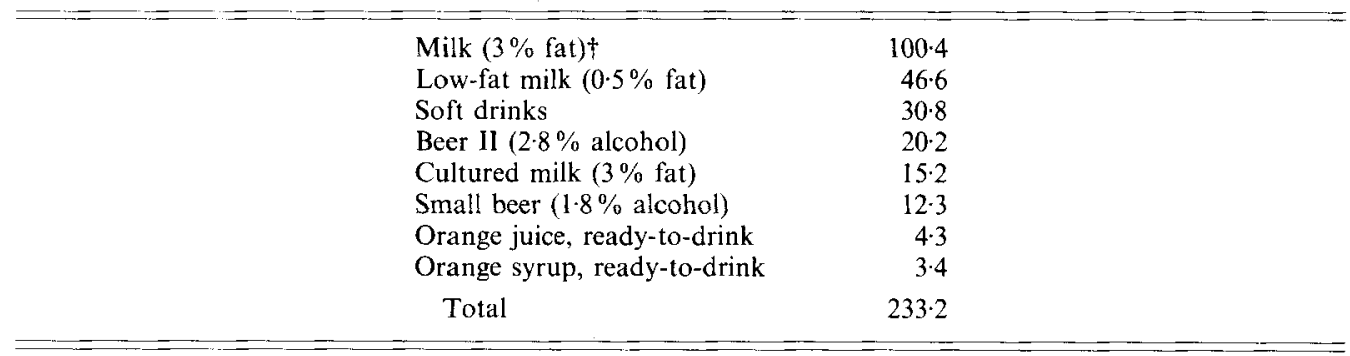

* For details, see p. 152.

$\dagger \mathrm{w} / \mathrm{w}$.

one city. This homogenate was freeze-dried in Petri dishes and crushed in a porcelain mortar. The homogenate was then weighed and stored in a plastic container. All containers used were colourless polyethylene plastic, and containers, knives, Petri dishes and mortars were all acid-washed to minimize metal contamination.

\section{Analytical procedures}

A Perkin-Elmer Model 5000 atomic absorption spectrophotometer (AAS) equipped with a HGA 500 graphite furnace with Zeeman background correction, AS-40 and AS-50 (for 
flame AAS) autosamplers and a Model 3600 data station with a printer were employed. Except for selenium and mercury determinations, accurately weighed samples of approximately $3 \mathrm{~g}$ dry weight were digested by boiling in concentrated nitric acid (ultrapure grade; Merck Co., Darmstadt, Germany) overnight. Calcium, magnesium, iron, zinc, manganese and copper were determined by flame AAS using a deuterium arc lamp for background correction (Perkin-Elmer, 1982).

Nickel, lead and cadmium were determined by electrothermal (ET) AAS employing pyrolytic platform graphite tubes and ammonium dihydrogen phosphate $(10 \mathrm{~g} / 1)$ for $\mathrm{Pb}$ and $\mathrm{Cd}$ or magnesium nitrate $(3 \mathrm{~g} / \mathrm{l})$ for $\mathrm{Ni}$ for matrix modification and the method of additions for quantification (Koirtyohann et al. 1982; Paakki \& Kumpulainen, 1985).

Molybdenum was determined by ETAAS using disodium EDTA ( $3 \mathrm{~g} / \mathrm{l}$ ) matrix modification and the method of additions for quantification (Paakki, 1986).

For Se determination, samples were digested using a mixture of concentrated nitric acid-perchloric acid-sulphuric acid $(6: 2: 2$ by vol; Kumpulainen et al. 1983). Se was separated from interfering elements, after their chelation by EDTA, by solvent extraction together with added $\mathrm{Cu}$ (II) used for matrix modification in the subsequent determination by graphite furnace AAS. The quantification was by the method of additions (Kumpulainen et al. 1983).

For the determination of $\mathrm{Hg}, 100-200 \mathrm{mg}$ dry wt samples were added to a $10 \mathrm{ml}$ mixture of concentrated $\mathrm{H}_{2} \mathrm{SO}_{4}$ and $\mathrm{HNO}_{3}(1: 2, \mathrm{v} / \mathrm{v})$ and kept for $2 \mathrm{~h}$ at $60^{\circ}$ in a water-bath. The solution was then quantitatively rinsed with water into a reaction flask, potassium permanganate solution $(100 \mathrm{~g} / \mathrm{l})$ was added gradually into the sample solution until the solution turned and stayed red for $1 \mathrm{~min}$. Hydroxylamine hydrochloride $(50 \mathrm{~g} / \mathrm{l})$ solution was then added until the colour disappeared. $\mathrm{Hg}$ was reduced by adding $5 \mathrm{ml}$ stannous chloride $(100 \mathrm{~g} / 1)$ followed by AAS determination at a $253.7 \mathrm{~nm} \mathrm{Hg}$ absorption line using the 'cold vapour technique' employing a $300 \mathrm{~mm}$ quartz cuvette for improved sensitivity. The quantification was by the method of additions. A $2.0 \mu \mathrm{g} \mathrm{Hg} / \mathrm{g}$ dry wt limit of quantification was obtained with the present method.

Reagent grade or ultrapure grade chemicals $(\mathrm{Hg}, \mathrm{Pb}, \mathrm{Cd}, \mathrm{Mg}$ and $\mathrm{Ni}$ ) and water purified by ion exchange and distillation were used throughout. A clean-air hood (Kojair Co., Tampere, Finland) meeting the Class 100 Standard (less than 100 particles sized $>1 \mu \mathrm{m}$ per cubic foot) was used in the final analytical steps for all elements determined.

The accuracy of the determinations made was confirmed using suitable biological reference materials (RM; Kumpulainen \& Paakki, 1987) including a total diet RM (TDD) prepared by the US Department of Agriculture (USDA) and provisionally certified for the elements determined by our laboratory on the basis of an interlaboratory comparison study (Kumpulainen et al. $1987 a$ ). Moreover, the very same TDD material is available from the National Bureau of Standards (NBS) provided with information values for most of the present elements. Table 3 presents the accuracy and precision we obtained for the elements determined in the diets of the present study.

\section{RESULTS AND DISCUSSION}

The content of mineral elements in the four market baskets, expressed per $\mathrm{MJ}$, are given in Table 4. There were rather small variations in mineral contents among the four towns, in general 5-10\%. Larger variations were observed for $\mathrm{Se}, \mathrm{Ni}$ and $\mathrm{Hg}$. The selected cities represent the four major geographic regions in Sweden. The results indicate that the regional differences in trace element and heavy metal contents of foods bought on the market are rather slight, or due to centralization of both the production and distribution of the major foods, or both. The market baskets were bought in October, a period when 
Table 3. Analytical accuracy as tested by determining the concentration (/kg dry weight) of mineral elements in the US Department of Agriculture Mixed Diet reference material National Bureau of Standards (NBS; RM 8431)

(Mean values and standard deviations for eight replicates of the reference material for each element)

\begin{tabular}{|c|c|c|c|c|c|c|}
\hline \multirow{3}{*}{ Element } & \multicolumn{2}{|c|}{ Present study } & \multirow{2}{*}{\multicolumn{2}{|c|}{$\begin{array}{l}\text { Provisional certified } \\
\text { values }(95 \% \text { median } \\
\text { confidence limits)* }\end{array}$}} & \multicolumn{2}{|c|}{ NBS information values $\dagger$} \\
\hline & \multirow{2}{*}{$\frac{\text { Mean }}{1.79}$} & \multirow{2}{*}{$\begin{array}{l}\text { SD } \\
0.08\end{array}$} & & & Mean & $\mathrm{SD}$ \\
\hline & & & 1.82 & 0.066 & 1.94 & 0.14 \\
\hline Magnesium (g) & $0 \cdot 660$ & 0.02 & $0 \cdot 64$ & $0 \cdot 015$ & $0 \cdot 65$ & 0.04 \\
\hline Iron (mg) & 38 & 2 & 34 & $1 \cdot 276$ & 37 & $2 \cdot 6$ \\
\hline Manganese $(\mathrm{mg})$ & 8.7 & $0 \cdot 47$ & $8 \cdot 24$ & $0 \cdot 421$ & $8 \cdot 12$ & $0 \cdot 31$ \\
\hline Zinc (mg) & $17 \cdot 0$ & 0.9 & 16.63 & 0.630 & $17 \cdot 0$ & 0.6 \\
\hline Copper (mg) & $3 \cdot 6$ & $0 \cdot 2$ & $3 \cdot 20$ & 0.237 & $3 \cdot 36$ & $0 \cdot 33$ \\
\hline Molybdenum (mg) & $0 \cdot 27$ & $0 \cdot 02$ & $0 \cdot 30$ & 0.023 & $0 \cdot 288$ & 0.029 \\
\hline Nickel (mg) & 0.64 & 0.04 & 0.64 & 0.076 & 0.644 & $0 \cdot 151$ \\
\hline Selenium $(\mu \mathrm{g})$ & 225 & 8 & 224 & $15 \cdot 8$ & - & - \\
\hline Chromium $(\mu \mathrm{g})$ & 145 & 22 & 125 & $26 \cdot 6$ & - & $\ldots$ \\
\hline Lead $(\mu \mathrm{g})$ & 151 & 16 & 150 & $17 \cdot 4$ & - & - \\
\hline Cadmium (mg) & 42 & 2 & 44 & $4 \cdot 7$ & - & - \\
\hline Mercury $(\mu \mathrm{g})$ & $7 \cdot 4$ & 0.7 & - & - & - & - \\
\hline
\end{tabular}

* See Kumpulainen et al. (1987a)

$\uparrow$ See NBS Report of Analysis, Reference Material 8431, Mixed Diet, NBS, Washington, DC, USA.

Table 4. Concentration of mineral elements in Swedish 'market-basket' samples* (/MJ) from four cities

\begin{tabular}{|c|c|c|c|c|}
\hline & Malmö & Göteborg & Stockholm & Sundsvall \\
\hline Calcium (g) & 108 & 104 & 101 & 97 \\
\hline Magnesium (mg) & 27 & 27 & 26 & 25 \\
\hline Iron (mg) & $1 \cdot 4$ & $1 \cdot 4$ & 1.5 & $1 \cdot 4$ \\
\hline Zinc (mg) & $1 \cdot 03$ & 1.04 & 1.06 & 1.08 \\
\hline Manganese $(\mathrm{mg})$ & $0 \cdot 33$ & 0.33 & 0.33 & 0.31 \\
\hline Copper (mg) & 0.09 & $0 \cdot 10$ & $0 \cdot 11$ & $0 \cdot 10$ \\
\hline Selenium $(\mu \mathrm{g})$ & $4 \cdot 0$ & $3 \cdot 8$ & $3 \cdot 3$ & $4 \cdot 2$ \\
\hline Molybdenum (ug) & 14 & 13 & 13 & 12 \\
\hline Nickel $(\mu \mathrm{g})$ & $8 \cdot 3$ & $7 \cdot 7$ & $5 \cdot 4$ & $7 \cdot 0$ \\
\hline Lead $(\mu \mathrm{g})$ & $1 \cdot 3$ & 1.5 & 1.7 & 1.4 \\
\hline Cadmium $(\mu \mathrm{g})$ & $1 \cdot 0$ & $1 \cdot 1$ & $1 \cdot 0$ & 1.0 \\
\hline Mercury $(\mu \mathrm{g})$ & $0 \cdot 24$ & $0 \cdot 16$ & 0.07 & $0 \cdot 14$ \\
\hline
\end{tabular}

* For details, see p. 152.

the supply of locally-produced foods (i.e. vegetables, root vegetables, fruit) is ample. The foods produced regionally throughout the year are milk and milk products, fresh meat and meat products to some degree. Grains are grown mostly in southern parts of Sweden. The grocery shops in which the market baskets were bought represented Sweden's three major wholesale chains. In a large grocery shop the supply of foods generally is so large that for most foods it will be possible to buy a locally-produced brand or a brand produced in another region of Sweden, and for some foods even an imported brand. This does not apply to liquid milk and fresh meat, however. The instructions to the persons responsible for 
Table 5. Analysed and calculated content of mineral elements in the average Swedish diet based on 'market-basket' samples*

\begin{tabular}{|c|c|c|c|}
\hline \multirow[b]{2}{*}{ Element } & \multicolumn{2}{|c|}{ Market baskets $\dagger$} & \multirow{2}{*}{$\begin{array}{c}\text { Calculated } \\
\text { per capila } \\
\text { supply }\end{array}$} \\
\hline & Analysed & Calculated & \\
\hline Calcium (g) & $1 \cdot 18$ & 1.20 & $1 \cdot 16$ \\
\hline Magnesium (mg) & 300 & 325 & 330 \\
\hline Iron (mg) & 16 & 18 & 18 \\
\hline Zinc (mg) & 12 & 12 & 11 \\
\hline Manganese (mg) & $3 \cdot 7$ & - & - \\
\hline Copper (mg) & $1 \cdot 2$ & - & - \\
\hline Selenium $(\mu \mathrm{g})$ & 44 & 38 & 38 \\
\hline Molybdenum $(\mu \mathrm{g})$ & 150 & - & - \\
\hline Nickel $(\mu \mathrm{g})$ & 82 & - & 230 \\
\hline Lead $(\mu \mathrm{g})$ & 17 & - & 30 \\
\hline Cadmium $(\mu \mathrm{g})$ & 12 & - & 14 \\
\hline Mercury $(\mu \mathrm{g})$ & $1 \cdot 8$ & - & - \\
\hline
\end{tabular}

* For details, see p. 152.

$\dagger$ Assumes a daily intake of $2 \mathrm{~kg}$ of the market-basket mixture, representing an average energy intake of 11.5 $\mathrm{MJ} / \mathrm{d}$.

$\ddagger$ Excluding export beer, wine and spirits; energy content $12 \mathrm{MJ} / \mathrm{d}$.

Table 6. Analysed content of some trace elements and heavy metals in typical Swedish diets based on 'market-basket' samples*

\begin{tabular}{|c|c|c|}
\hline Element & $\begin{array}{c}\text { Weekly diet } \dagger \\
1980\end{array}$ & $\begin{array}{c}\text { Food basket } \ddagger \\
1987\end{array}$ \\
\hline Iron (mg) & 14 & 16 \\
\hline Zinc (mg) & $8 \cdot 6$ & 12 \\
\hline Manganese (mg) & $2 \cdot 6$ & $3 \cdot 7$ \\
\hline Copper (mg) & $1 \cdot 5$ & $1 \cdot 2$ \\
\hline Lead $(\mu \mathrm{g})$ & 27 & 17 \\
\hline Cadmium $(\mu \mathrm{g})$ & 10 & 12 \\
\hline
\end{tabular}

* For details, see p. 152.

† Slorach et al. (1983); energy content $11.7 \mathrm{MJ} / \mathrm{d}$.

$\$$ Present study; energy content $11.5 \mathrm{MJ} / \mathrm{d}$.

making the purchases were to buy the brands usually bought or the brand available at a reduced price.

In Table 5, the daily supply of mineral elements was calculated from the analyses assuming a daily intake of $2 \mathrm{~kg}$ food, which corresponds to the daily per capita supply of energy in Sweden. For comparison, intakes calculated from values in the Swedish food tables (Becker, 1991) are given. As can be seen, there is good agreement between the analysed and calculated values for the market baskets. There is also good agreement when the calculations for the total per capita supply are compared with the values for the market baskets showing that, for these minerals, the composition of the market baskets is representative of the average Swedish diet. Thus, the results show that the Swedish food tables provide relevant information for the estimation of dietary intake of $\mathrm{Ca}, \mathrm{Mg}, \mathrm{Fe}, \mathrm{Zn}$ and Se.

The content of $\mathrm{Ca}$ in the market baskets was higher than, and that of $\mathrm{Mg}, \mathrm{Fe}, \mathrm{Zn}$ and 
Se close to, the daily allowances for adults provided in the current Swedish recommendations (Swedish National Food Administration, 1989). The contents of $\mathrm{Mn}$ and Mo were within, whereas that of $\mathrm{Cu}$ was below, the safe and adequate daily dietary intake values given in the US recommended dietary allowances (RDA) for 1989 (Food and Nutrition Board, National Research Council, 1989).

The energy content of the market baskets (11.5 MJ) corresponds to the Swedish reference value for adult men with low physical activity (Swedish National Food Administration, 1989). For groups with lower energy requirements, e.g. women, the nutrient density of the food baskets was marginal compared with these same recommendations (Swedish National Food Administration, 1989).

There are rather few Swedish studies in which the mineral element contents of diets has been analysed. In an earlier study by Slorach et al. (1983), a weekly diet designed from Swedish food balance sheet data for 1975 was analysed for the content of heavy metals and some trace elements. The diets were prepared in 1980. In Table 6 the results of the present investigation are compared with those results. The levels are comparable, although the present food baskets contained somewhat more $\mathrm{Zn}$ and $\mathrm{Mn}$ and less $\mathrm{Pb}$ than the weekly diet from 1980.

In a dietary survey of Swedish adults, duplicate portions of daily diets collected in 1970 were analysed for several mineral elements (Borgström et al. 1975, 1979). The mean levels of $\mathrm{Ca}, \mathrm{Mg}, \mathrm{Fe}, \mathrm{Zn}, \mathrm{Cu}$ and $\mathrm{Se}$ found in these diets, expressed per $\mathrm{MJ}$, were similar to the levels found in the present market-basket survey.

The content of $\mathrm{Pb}$ in the market basket was $17 \mu \mathrm{g} /$ person per $\mathrm{d}$, which is somewhat lower than that reported in earlier Swedish studies (Schütz, 1979a; Slorach et al. 1983). In a recent study, the mean $\mathrm{Pb}$ content of duplicates of seven consecutive daily diets collected from fifteen women living in Stockholm was found to be $26 \mu \mathrm{g}$ (Vahter et al. 1990). The market-basket diets in the present study did not contain alcoholic beverages, which are estimated to contribute about $10 \mu \mathrm{g} \mathrm{Pb}$ /person per $\mathrm{d}$. The total intake is, thus, estimated to be $27 \mu \mathrm{g} / \mathrm{d}$ or $190 \mu \mathrm{g} /$ week. The intake is considerably lower than the provisional tolerable weekly intake of $3 \mathrm{mg}$ for an adult (corresponding to $0.05 \mathrm{mg} / \mathrm{kg}$ body-wt) set by a Food and Agriculture Organization/World Health Organization Expert Committee (World Health Organization, 1972).

The content of $\mathrm{Cd}$ in the market baskets $(12 \mu \mathrm{g})$ corresponds to a weekly intake of $84 \mu \mathrm{g} /$ person. This is similar to intakes found in earlier (Schütz $1979 a$; Slorach et al. 1983) and recent (Vahter et al. 1990) Swedish studies, and much lower than the provisional weekly intake of $0.4-0.5 \mathrm{mg} /$ person (body-wt $60-70 \mathrm{~kg}$ ) established by a Food and Agriculture Organization/World Health Organization Expert Committee (World Health Organization, 1989). The analysed content also agrees with the average dietary intake of Cd calculated from the Cd levels in individual foods (Table 5).

The food basket content of $\mathrm{Hg}$ was low, $1.8 \mu \mathrm{g} /$ person per $\mathrm{d}$. This corresponds to a weekly intake of $13 \mu \mathrm{g} /$ person, which is remarkably low compared with the provisional tolerable weekly intake at $0.3 \mathrm{mg}(0.2 \mathrm{mg}$ methylmercury)/person set by a Food and Agriculture Organization/World Health Organization Expert Committee (World Health Organization, 1972). The level of $\mathrm{Hg}$ in the market baskets is lower than the $3.6-5.6$ $\mu \mathrm{g} /$ person per $\mathrm{d}$ found in duplicate daily diets of adults collected in 1969-71 in southern Sweden (Schütz, 1979 b). Although the studies are not directly comparable, the results of the present study indicate a decrease in the general level of $\mathrm{Hg}$ in foods. This is further supported by analytical results for individual foods (Kolar \& Nickels, 1981).

The content of $\mathrm{Ni}$ in the market baskets was $80 \mu \mathrm{g} /$ person per $\mathrm{d}$. Tea, coffee and alcoholic beverages (not included in the food baskets) are estimated to provide an additional $10-20 \mu \mathrm{g} /$ person per $\mathrm{d}$. The level is low compared with results from earlier 
Table 7. Content of mineral elements $(/ M J)$ in total diets from various countries

\begin{tabular}{|c|c|c|c|c|}
\hline Element & $\begin{array}{c}\text { Sweden* } \\
1987\end{array}$ & Finland $\dagger$ & $\begin{array}{c}\text { Netherlandst } \\
\text { 1984-6 }\end{array}$ & $\begin{array}{c}\text { USA } \$ \\
1982-4\end{array}$ \\
\hline Calcium (mg) & 103 & 115 & 102 & 109 \\
\hline Magnesium (mg) & 26 & 35 & 33 & 28 \\
\hline Iron $(\mathrm{mg})$ & $1 \cdot 4$ & $1 \cdot 6$ & $1 \cdot 8$ & $1 \cdot 6$ \\
\hline Zinc (mg) & 1.04 & $1 \cdot 23$ & 1.04 & 1.5 \\
\hline Manganese (mg) & $0 \cdot 32$ & 0.52 & $\mathrm{NA}$ & 0.26 \\
\hline Copper (mg) & $0 \cdot 10$ & $0 \cdot 14$ & $0 \cdot 11$ & 0.11 \\
\hline Selenium $(\mu \mathrm{g})$ & $3 \cdot 8$ & $11 \cdot 5$ & $5 \cdot 5$ & 9 \\
\hline Molybdenum $(\mu \mathrm{g})$ & 13 & 10 & $\mathrm{NA}$ & 12 \\
\hline Nickel $(\mu \mathrm{g})$ & $7 \cdot 1$ & $12 \cdot 5$ & $\mathrm{NA}$ & 15 \\
\hline Lead $(\mu \mathrm{g})$ & $1 \cdot 5$ & $1 \cdot 6$ & $2 \cdot 4$ & NA \\
\hline Cadmium $(\mu \mathrm{g})$ & $1 \cdot 0$ & $1 \cdot 1$ & $1 \cdot 6$ & NA \\
\hline Mercury $(\mu \mathrm{g})$ & $0 \cdot 16$ & NA & $0-05$ & NA \\
\hline \multicolumn{5}{|c|}{$\begin{array}{l}\text { NA, not assessed. } \\
\text { * Present study. } \\
+ \text { Kumpulainen et al. }(1987 \mathrm{~b}) \text {; based on 'food-basket' survey data. } \\
+ \text { van Dokkum et al. }(1989) ; 18 \text {-year-old Dutch males. } \\
\$ \text { Pennington et al. }(1986) \text {, Pennington \& Jones }(1987) ; 14 \text { - to 16-year-old boys. }\end{array}$} \\
\hline
\end{tabular}

Swedish and international studies (Abdulla \& Svensson, 1979; Pennington et al. 1986; Kumpulainen et al. 1987 b; Kardinaal, 1988).

In Table 7, the results of the present market-basket survey are compared with results from some international studies in which the energy levels of the collected diets were stated. The results are expressed per MJ since the sampling designs differ. Generally, the content of essential elements is at a similar level, except for Se which is the most marked exception. The concentration of heavy metals varies somewhat more, but the levels are generally low.

The selection of the Swedish and Finnish market baskets was based on values for the annual per capita consumption, and the analyses were made on a mixture of all foods. The Dutch and US diets were composed from data from dietary surveys, and the mineral contents of the baskets were obtained by combining the consumption data with analytical data for various food groups. In the present study the selected sixty foods represented $76 \%$ of the annual consumption on a weight basis. In the studies based on individual diets (Pennington et al. 1986; Pennington \& Jones, 1987; van Dokkum et al. 1989) more foods (220-230) were included in the market baskets, which means that a larger number of foods represented each food group. However, in the present study all major food groups were represented and weighed according to the average consumption. The only food group not included was canned fruit and vegetables, which do not contribute to any significant degree to the average intake of the mineral elements included in the study. For individuals, however, canned foods could be an important source of lead.

In conclusion, the results of the present study show that a market-basket survey based on detailed food balance sheet data is a useful method for obtaining relevant information on the average dietary content and supply of various minerals. It can also be used to check the reliability of results obtained from calculations based on mineral contents of individual foods.

The food-basket survey was supported by grants from the National Institute of Radiation Protection. On behalf of the Swedish National Food Administration, the authors want to thank the staff at the local health authorities for their help with the purchase of the food baskets. They also thank Christina Normark and Clary Pousette, National Food 
Administration, for preparation of the samples, and Leena Puura, Agricultural Research Centre, Finland, for skilful analytical work.

\section{REFERENCES}

Abdulla, M. \& Svensson, S. (1979). Nutrition and old age. Chemical analyses of what old people eat and their states of health during 6 years of follow-up. Chromium and nickel. Scandinavian Journal of Gastroenterology 14, Suppl. 52, 176-180.

Becker W. (1991). Den svenska kostens näringsinnehåll 1980-88 (The nutrient content of the Swedish diet 1980-88). SLV-rapport 1991. Uppsala: National Food Administration (In the Press.)

Borgström B., Nordén Å., Åkesson B., Abdulla, M. \& Jägerstad, M. (1979). Nutrition and old age. Chemical analyses of what old people eat and their states of health during 6 years of follow-up. Scandinavian Journal of Gastroenterology 14, Suppl. 52.

Borgström B., Nordén Å., Akesson B. \& Jägerstad, M. (1975). A study of food consumption by the duplicate portion technique in a sample of the Dalby population. Scandinavian Journal of Social Medicine Suppl. 10.

Food and Nutrition Board, National Research Council (1989). Recommended Dietary Allowances, 10 th ed. Washington, DC: National Academy of Sciences.

Kardinaal, A. M. F. (1988). Een dieet bij nickelallergie (A diet for nickel allergy). Voeding 49, $182-185$.

Koirtyohann, S. R., Kaiser, M. L. \& Hinderberger, E. J. (1982). Food analysis for lead using furnace atomic absorption and a L'vov platform. Journal of the Association for Official Analytical Chemists 65, $999-1004$.

Kolar, K. \& Nickels, C. (1981). Totalkvicksilverhalten i kött, lever och njure från nötkreatur och svin. (Total mercury content in meat, liver and kidney from cattle and pig). Rapport G-16-0561. Kävlinge: Köttforskningsinstitutet.

Kumpulainen, J., Mutanen, M., Paakki, M. \& Lehto, J. (1987a). Validity of calculation method in estimating mineral element content. Vär Föda 39, Suppl. 1, 75-82.

Kumpulainen, J. \& Paakki, M. (1987). Analytical quality control program employed by the Trace Elements in Foods and Diets Sub-network of the FAO European Cooperative Network on Trace Elements. Fresenius' Zeitschrift fur Analytische Chemie 326, 684-689.

Kumpulainen, J., Raittila, A.-M., Lehto, J. \& Koivistoinen, P. (1983). Electrothermal atomic absorption spectrometric determination of selenium in foods and diets. Journal of the Association for Official Analytical Chemists 66, 1129-1135.

Kumpulainen, J., Sinisalo, M., Paakki, M. \& Tahvonen, R. (1987b). Mineral element composition of a nationally representative Finnish market basket diet. Kemia-Kemi 14, 10B, Abstr. 10.38.

Kumpulainen, J. \& Tahvonen, R. (1989). Report on the activities of the sub-network on trace elements' status in food. In Report on the 1989 consultation of the European cooperative research network on trace elements (Lausanne, Switzerland), pp. 5-8. Rome: Food and Agriculture Organization of the United Nations.

Øhlander, E. M., Becker, W. \& Bruce, $\AA$ (1991). Monitoring dietary radiocesium intake in Sweden after the Chernobyl Accident. In Monitoring dietary intakes, ILSI Monographs, pp. 191-204 [I. MacDonald, editor]. New York: Springer-Verlag.

Paakki, M. (1986). Determination of molybdenum in staple foods by electrothermal atomic absorption spectrometry. Kemia-Kemi 13, 11, Abstr. 9.23.

Paakki, M. \& Kumpulainen, J. (1985). Determination of $\mathrm{Pb}, \mathrm{Cd}$ and $\mathrm{Se}$ in staple foods and total diets by electrothermal atomic spectrometry using Zeeman effect background correction. 10th Nordic Atomic Spectroscopy and Trace Element Conference, Book of Abstracts, p. 46. Turku: The Association of Finnish Chemical Societies.

Pennington, J. A. \& Jonss, J. W. (1987). Molybdenum, nickel, cobalt, vanadium, and strontium in total diets. Journal of the American Dietetic Association 87, 1644-1650.

Pennington, J. A., Young, B. E., Wilson, D. B., Johnson, R. D. \& Vanderveen, J. E. (1986). Mineral content of foods and total diets: The selected minerals in food survey, 1982 to 1984. Journal of the American Dietetic Association 86, 876-891.

Perkin-Elmer (1982). Analytical Methods for Atomic Absorption Spectrophotometry. Norwalk, CT: Perkin-Elmer.

Schütz, A. (1979a). Nutrition and old age. Chemical analyses of what old people eat and their states of Health during 6 years of follow-up. Cadmium and lead. Scandinavian Journal of Gastroenterology 14, Suppl. 52, $223-231$.

Schütz, A. (1979 b). Nutrition and old age. Chemical analyses of what old people eat and their states of Health during 6 years of follow-up. Mercury. Scandinavian Journal of Gastroenterology 14, Suppl. 52, 232-235.

Sinisalo, M., Kumpulainen, J., Paakki, M. \& Tahvonen, R. (1989). Content of major and minor mineral elements in weekly diets of eleven Finnish hospitals. Journal of Human Nutrition and Dietetics 2, 43-48.

Slorach, S., Gustafsson, I.-B., Jorhem, L. \& Mattsson, P. (1983). Intake of lead, cadmium and certain other metals via a typical Swedish weekly diet. Vår Föda 35, Suppl. 1, 3-16.

Statens jordbruksnämnd (1986). Konsumtionen av livsmedel 1983-85. (The consumption of food 1983-85). Jönköping: Statens Jordbruksnämnd. 
Swedish National Food Administration (1989). Swedish Nutrition Recommendations 2nd ed. SLV-rapport 12. Uppsala: National Food Administration.

Vahter, M., Berglund, M., Friberg, L., Jorhem, L., Lind, B., Slorach, S. \& Åkesson, A. (1990). Dietary intake of lead and cadmium in Sweden. Vär Föda 44, Suppl. 2, 1-16.

van Dokkum, W., De Vos, R. H., Muys, Th. \& Wesstra, J. A. (1989). Minerals and trace elements in total diets in the Netherlands. British Journal of Nutrition 61, 7-15.

Varo, P. \& Koivistoinen, P. (1980). Mineral element composition of Finnish foods. XII. General discussion and nutritional evaluation. Acta Agriculturae Scandinavica 22, Suppl., 165-171.

Varo, P., Nuurtamo, M., Saari, E., Räsänen, L. \& Koivistoinen, P. (1980). Mineral element composition of Finnish foods. XI. Comparison of analytical and computed compositions in some simulated total diets. Acta Agriculturae Scandinavica 22, Suppl., 161-164.

World Health Organization (1972). Sixteenth Report of the Joint FAO/WHO Expert Committee on Food Additives. WHO Technical Report Series no. 505. Geneva: WHO.

World Health Organization (1989). Thirty-third Report of the Joint FAO/WHO Expert Committee on Food Additives. WHO Technical Report Series no. 776. Geneva: WHO. 